\title{
Vücut Geliştirme Sporu Yapan Bireylerde Alt ve Üst Ekstremite İşlevsel Performans Düzeyi ile Beden Algısı Arasındaki İlişkinin İncelenmesi*
}

\author{
Çetin SAYACA ${ }^{1}$, Yener Emre SEVGíLi ${ }^{2}$ \\ 1 Uludağ Üniversitesi Sağlık Bilimleri Fakültesi Fizyoterapi ve Rehabilitasyon Bölümü, Bursa. \\ 2 Üsküdar Üniversitesi Sağlık Bilimleri Fakültesi Fizyoterapi ve Rehabilitasyon Bölümü, İstanbul.
}

\section{ÖZET}

$\mathrm{Bu}$ çalışma, vücut geliştirme sporu yapan bireylerde alt ve üst ekstremite işlevsel performans düzeyi ile beden algısı arasındaki ilişkiyi incelemek amacıyla planlandı. Çalışmaya vücut geliștirme sporu yapan, yaş ortalaması 25,00 33,18 yıl olan 30 sağlıklı erkek dâhil edildi. Çalışmaya katılan bireylerin demografik özellikleri kaydedildikten sonra alt ve üst ekstremite işlevsel performans düzeyleri ile beden algıları değerlendirildi. Üst ekstremite işlevsel performans düzeyi ile beden algısı değerleri arasında pozitif yönlü orta şiddette ilişki bulundu (r:0,489; p:0,006). Vücut geliştirme sporu yapan bireylerin üst ekstremite işlevsel performans düzeyi arttıkça beden algıları da artmaktadır. Üst ekstremite işlevsel performans düzeyi ile alt ekstremite işlevsel performans düzeyi ve vücut kütle indeksi (VKI) değerleri arasında, alt ekstremite işlevsel performans düzeyi ile beden algısı ve VKİ değerleri arasında ise ilișki bulunamadı $(\mathrm{p}>0,05)$. Üst ekstremite işlevsel performans düzeyindeki artış beden algısını olumlu etkilerken alt ekstremite işlevsel performans düzeyi ile beden algısı arasında herhangi bir ilişki bulunamadı. Vücut geliştirme sporu yapan bireylerin beden algıları ayrıntılı değerlendirilmeli ancak vücut kısımları arasındaki dengeyi beden sağlığını ön planda tutulacak şekilde eğitim programları düzenlenmelidir.

Anahtar Kelimeler: Beden Algısı. İşlevsel Performans. Vücut Geliştirme.

Investigation of the Relationship Between Lower and Upper Extremity Functional Performance Levels and Body Perception in Individuals Doing Bodybuilding Sports

\begin{abstract}
This study was planned to examine the relationship between lower and upper extremity functional performance levels with body perception in individuals who exercise bodybuilding. The study included 30 healthy men who were engaged in bodybuilding sports, with an average age of $25.00 \pm 3.18$ years. After the demographic characteristics of the individuals participating in the study were recorded, the levels of lower and upper extremity functional performance, and body perceptions were evaluated. A positive moderate correlation was found between upper extremity functional performance level and body perception values (r: 0.498; p: 0.006). Body perception of individuals increases when the upper extremity functional performance level increases. No relationship was found between upper limb functional performance level and lower limb functional performance level, and body mass index (BMI) values, between lower limb functional performance level and body perception, and BMI values ( $>>0.05$ ). While the increase in the functional performance level of the upper limb positively affects the perception of the body, no relation was found between the lower extremity functional performance level and body perception. Body perception of individuals engaged in bodybuilding sports should be evaluated in detail, but training programs should be organized in such a way that the balance between the body parts should be prioritized by the body health.
\end{abstract}

Key Words: Body Perception. Functional Performance. Bodybuilding.

Geliș Tarihi: 28.Ocak.2020

Kabul Tarihi: 10.Haziran.2020

* Uluslararası Sağlıklı Yaşam Kongresi'nde (10-11 Ekim 2019, İstanbul) sözel bildiri olarak sunulmuştur.

Dr. Çetin SAYACA

Uludağ Üniversitesi Sağlık Bilimleri Fakültesi Fizyoterapi ve Rehabilitasyon Bölümü

Özlüce Görükle Kampüsü, PK: 16059 Nilüfer/Bursa

Tel: 05436218023

E-posta: cetinsayaca@uludag.edu.tr

Yazarların ORCID ID Bilgisi:

Cetin SAYACA: 0000-0002-6731-1677

Yener Emre SEVGiLí: 0000-0001-7215-8796
Beden algıs1, son yıllarda üzerinde durulan önemli konulardan biridir ${ }^{1}$. Bireyin bedenini zihinde nasıl göründüğüne dair sahip olduğu fikir, duygu ve düşünce olarak açıklanmaktadır ${ }^{2,3}$. Diğer bir tabirle, bireyin vücut kısımlarının fonksiyonlarını kendi kendine değerlendirerek olumlu ya da olumsuz fikir üretmesidir ${ }^{4}$. Yaş, cinsiyet, kilo, sağlık, zaman ve topluma göre değişkenlik göstermektedir². Düzenli yapılan spor beden algısını olumlu etkilemektedir ${ }^{2,5}$.

Vücut geliştirme sporu her yaştaki bireyleri sağlıklı, zinde ve formda tutmak için kasları kuvvetlendiren, geliştiren ve estetik görünüm kazandıran çok yönlü bir 
spor branşıdır ${ }^{6}$. Vücut geliştirme sporu yapan bireyler gövde görünümlerinden orta düzeyde memnun iken yüz ve ekstremite görünümünden pek memnun olmadıkları ifade edilmiştir ${ }^{7}$. Vücut geliştirme sporu yapan bireyler görünümünden memnun olmadıkları ekstremitelerini geliştirmek ve memnuniyet düzeylerini artırmak için özellikle de üst ekstremite eğitimine odaklandıkları görülmektedir.

Sprint, firlatma ve ağırlık kaldırma gibi aktiviteler patlayıcı ve güç isteyen faaliyetler olup yüksek oranda kuvvete ihtiyaç duyulur ${ }^{8}$. Sağlık topu firlatma ve hoplama ile kassal kuvvet arasında kuvvetli bir ilişki vardır ${ }^{9}$. Literatürde, vücut geliştirme sporu yapan bireylerin ekstremitelerinin görünümlerinden memnun olmak için yaptıkları kuvvet eğitimleri sonucunda elde ettikleri alt ve üst ekstremite işlevsel performansları ile beden algısı arasında bir ilişki olup olmadığını inceleyen bir çalışmaya rastlanmamıştır. $\mathrm{Bu}$ çalışmanın amacı, vücut geliştirme sporu yapan bireylerde alt ve üst ekstremite işlevsel performans düzeyi ile beden algısı arasındaki ilişkiyi incelemektir. $\mathrm{Bu}$ çalışmanın hipotezleri "vücut geliştirme sporu yapan bireylerde alt ve üst ekstremite işlevsel performans düzeyi ile beden algısı arasındaki bir ilişki yoktur" ve "vücut geliştirme sporu yapan bireylerde alt ve üst ekstremite işlevsel performans düzeyi ile beden algısı arasındaki bir ilişki vardır" olarak belirlenmiştir.

\section{Gereç ve Yöntem}

Çalışma protokolü, girişimsel olmayan etik kurul tarafından onaylandı. Tüm bireyler, değerlendirme öncesinde çalışmanın kapsamı ve izlekler hakkında bilgilendirildi. Çalışma, Helsinki Bildirgesi'nin etik yönergeleri ile ilkelerine göre yürütüldü ve katılan tüm bireyler bilgilendirilmiş gönüllü olur formunu imzaladilar.

Çalışmaya rekreasyonel amaçlı vücut geliştirme sporu yapan, yaş ortalaması $25,00 \pm 3,18$ yıl olan 30 sağlıklı erkek dâhil edildi. Çalışmaya katılan bireyler eğitmenler tarafindan önerilen egzersiz programlarını uyguluyor idiler. Yaşı 18-30 yıl aralığında olan, en az altı aydır düzenli olarak haftada 3 gün ve üzeri vücut geliştirme sporu yapan erkek bireyler çalışmaya dahil edildi. Herhangi bir cerrahi operasyon geçirmiş olan, fiziksel engeli olan, psikolojik hastalık tanısı olan, diş görünümü etkileyecek herhangi bir sağlık problemi olan ve vücut geliştirme sporu dışında başka bir spor ile ilgilenen bireyler çalışmaya dahil edilmedi.

\section{Değerlendirme}

Çalışmaya katılan bireylerin demografik bilgileri (yaş, boy, kilo) kaydedildikten sonra değerlendirmeleri aynı fizyoterapist tarafindan yapıldı. Değerlendirme öncesi her birey beş dakika koşmayacak şekilde hızlı adım- larla yürütülerek genel ısınma yapıldı. Üst ekstremite lokal ısınma için sağlık topunu yukarı doğru üç kez atması, alt ekstremite lokal ısınması için ise beş kez olduğu yerden yukarı doğru zıplaması istendi. Genel ve lokal ısınmalar ile ölçümler arasında ikişer dakika dinlenme arası verildi.

Üst ekstremite işlevsel performansın değerlendirilmesi: Üst ekstremite işlevsel performansı değerlendirmek amacıyla $2,7 \mathrm{~kg}$ ağırlığındaki sağlık topu firlatma testi uygulandı. Birey, başlangıç çizgisinin bir adım gerisinde ayakta dururken bir adım alarak sağlık topunu göğüs seviyesinden tüm gücüyle ileri doğru attı. Başlangıç çizgisinden topun düştüğü nokta arasındaki mesafesi ölçülerek cm cinsinden kaydedildi ${ }^{10}$. Bireyden testi üç kez tekrar etmesi istendi ve en yüksek değer kabul edildi.

Alt ekstremite işlevsel performansın değerlendirilmesi: Alt ekstremite işlevsel performansı değerlendirilmesi amaciyla tek bacak öne hoplama testi (OneLegged Hop Test) kullanıld ${ }^{11}$. Birey, baskın taraf alt ekstremitesi üzerinde dururken renkli bir bant ile işaretlenmiş çizgiden öne doğru sıçramaları istendi ve topuk ile başlangıç çizgisi arasındaki mesafe ölçülerek cm cinsinden kaydedildi ${ }^{12}$. Bireyden testi üç kez tekrar etmesi istendi ve en yüksek değer kabul edildi. Değerlendirme öncesi bireylerin baskın taraf alt ekstremitelerini belirlemek amacıyla önlerine top konuldu ve bu topa vurmaları istendi. Topa vurdukları ayak baskın taraf alt ekstremite olarak kabul edildi.

Beden algısının değerlendirilmesi: Bireyin beden algısı, Vücut Algısı Ölçeği (VAÖ) ile değerlendirildi. Ölçek her bir maddesi bir organ veya bedenin bir bölümü ya da işlevi ile ilgili olan 40 maddeden oluşmaktadır. Her bir madde 1'den 5'e kadar değişen puanlar ile değerlendirilmekte olup toplam puan 40 ile 200 arasında değişmektedir. Ölçeğin kesme puanı 135 olup, 135 altında puana sahip olanlar bireylerin beden algısı düşük olarak tanımlanmıştır. Bu çalışmada, anketin Türkçe sürümü kullanıldı ${ }^{13}$.

\section{Istatistiksel Analiz}

Çalışmadan elde edilen veriler IBM-SPSS programı 20. versiyon yazılımı kullanılarak analiz edildi (IBM Corp.,Armonk, New York, United States). Sayısal verilerin normal dağılımları Kolmogorov-Smirnov/ Shapiro-Wilk testi ve görsel yöntemler (Histogram) kullanılarak değerlendirildi. Analiz sonucunda üst ekstremite işlevsel performans ve beden algısı değerlerinin normal dağılmadıkları saptandı. $\mathrm{Bu}$ verilerin logaritması alınarak istatistiksel transformasyon uygulandı ve işlem sonrasında sayısal verilerin normal dağılım gösterdikleri saptandı. Normal dağılım gösteren sayısal verilerin tanımlayıcı istatistiksel analizlerinde ortalama ve standart sapma değerleri belirtildi. Vücut kütle indeksi (VKİ), üst-alt ekstremite işlevsel performans düzeyi ve beden algısı aralarındaki ilişki Pearson korelasyon analizi ile değerlendirildi. Kore- 


\section{Performans Düzeyleri ile Beden Algısı İlişkisi}

lasyon katsayısı 0,30 ile 0,39 arasında zayıf düzeyde ilişki, 0,40 ile 0,59 arasında orta düzey ilişki, 0,60 ila 0,69 arasında iyi düzeyde ilişki, 0,70 ila 0,75 arasında çok iyi düzeyde ilişki ve 0,75-1,00 arasında yüksek düzeyde ilişki olduğunu gösterir. Anlamlılık düzeyi $\mathrm{p}<0,05$ olarak kabul edildi.

\section{Bulgular}

Çalışmaya katılan bireylere ait tanımlayıcı veriler Tablo I'de verilmiştir. Üst ekstremite işlevsel performans düzeyi ile beden algısı değerleri arasında pozitif yönlü orta şiddette ilişki bulundu (r:0,489; p:0,006) Vücut geliştirme sporu yapan bireylerin üst ekstremite işlevsel performans düzeyi arttıkça beden algıları da artmaktadır. Üst ekstremite işlevsel performans düzeyi ile alt ekstremite işlevsel performans düzeyi ve vücut kütle indeksi (VKİ) değerleri arasında ilişki bulunamadı. Alt ekstremite işlevsel performans düzeyi ile beden algısı ve VKİ değerleri arasında ise ilişki bulunamadı $(\mathrm{p}>0,05)$ (Tablo II).

Tablo I. Çalışmaya katılan bireylere ait tanımlayıc veriler.

\begin{tabular}{|lcc|}
\hline & Ortalama \pm SS & $\begin{array}{c}\text { Minimum- } \\
\text { Maksimum }\end{array}$ \\
\hline Yaş (yıl) & $25,00 \pm 3,18$ & $19,00-30,00$ \\
\hline VKi (kg/m²) & $23,61 \pm 1,69$ & $19,62-26,54$ \\
\hline Sağlık Topu Fırlatma (cm) & $676,93 \pm 76,93$ & $586,00-880,00$ \\
\hline Öne Hoplama Testi (cm) & $146,53 \pm 22,94$ & $110,00-200,00$ \\
\hline VAÖ (puan) & $172,00 \pm 23,20$ & $129,00-200,00$ \\
\hline
\end{tabular}

VKİ: vücut kütle indeksi; VAÖ: Vücut Algısı Ölçeği; SS: standart sapma; kg: kilogram; m: metre; cm: santimetre.

Tablo II. Vücut kütle indeksi, sağlık topu firlatma, öne hoplama testi ve beden algısı değerlendirme sonuçları arasındaki ilişkinin incelenmesi.

\begin{tabular}{|lccc|}
\hline \multicolumn{1}{|c}{ r/p } & $\begin{array}{c}\text { Sağlık Topu } \\
\text { Firlatma }\end{array}$ & $\begin{array}{c}\text { Öne Hoplama } \\
\text { Testi }\end{array}$ & VAÖ \\
\hline \multirow{2}{*}{ Vki } & $-0,064$ & $-0,069$ & 0,132 \\
& 0,735 & 0,717 & 0,485 \\
\hline \multirow{2}{*}{ Sağlık Topu FIrlatma } & \multirow{2}{*}{1} & 0,338 & 0,489 \\
& & 0,068 & $0,006^{\star}$ \\
\hline \multirow{2}{*}{ Öne Hoplama Testi } & - & 1 & 0,056 \\
& & 1 & 0,769 \\
\hline
\end{tabular}

r: korelasyon katsayısı; $\mathrm{p}<0.05$; Pearson korelasyon analizi;

*: İstatistiksel anlamlılığı ifade etmektedir.

\section{Tartışma ve Sonuç}

$\mathrm{Bu}$ çalışmada, üst ekstremite işlevsel performans düzeyindeki artış beden algısını olumlu etkilerken, alt ekstremite işlevsel performans düzeyindeki artışın beden algısını etkilemediği saptandı. Alt ekstremite işlevsel performans düzeyi ile VKİ, üst ekstremite işlevsel performans düzeyi ve beden algısı arasında ise bir ilişki bulunamadi. Ayrıca beden algısı ile VKİ arasında ise herhangi bir ilişki olmadığı saptandı.

Literatürde, egzersizin beden alg1sı üzerine olumlu etkileri olduğu bilinmesine rağmen ${ }^{14,15}$ vücut geliştirme sporu yapan bireylerde beden algısı ölçek puanının kabul edilen kesme değerinin yarısından daha az değere sahip olduğunu gösteren çalışmalarda bulunmakta$\operatorname{dir}^{16}$. Bu çalışmaya katılan bireylerin beden algısı değer ortalaması ölçeğin kesme değerinin çok üzerinde idi. Bu puan, ölçeğin kabul edilen kesme değerinin çok üzerinde olduğunu göstermektedir. Elde edilen bu sonuç, vücut geliştirme sporu yapan bireylerin beden algılarının yüksek olduğu ve egzersizin yapılma amaçlarından biri olan beden algısını kazandırmada etkili olmuş olabileceğ $\mathrm{i}^{1}$ ve egzersizin en önemli yapılma amaçlarından biri olan fiziksel iyi görünme ile toplumsal kabul görme düzeyini kazandırmış olabilir ${ }^{17}$.

Leister ve ark. tarafindan sağlıklı sedanter gençler üzerinde yaptıkları öne hoplama testinin referans değerlerinin araştırıldığı bir çalışmada, erkek bireylerin baskın tarafları ile ortalama 158,2 $\pm 29 \mathrm{~cm}$ ileriye hopladığı kaydedilmiştir ${ }^{18}$. Çalışmaya katılan erkek bireylerin yaş ortalaması ve VKİ değer ortalamaları bizim çalışmamıza katılan bireylerin ortalama değerlerine göre daha yüksek idi. Bu çalışmaya katılan bireyler daha genç ve VKİ ortalamaları daha düşük olmasına rağmen elde edilen performans da daha düşük çıkmıştır. Performansın bu kadar düşük çıkmasının bir sebebi genetik faktörler olabilir. Ayrıca bu çalışmaya katılan, vücut geliştirme sporu yapan bireylerin çoğu özellikle üst ekstremite kasları üzerine yoğunlaştıkları ve egzersiz sürelerinin çoğunu burada yer alan kasları geliştirmek için harcadıkları gözlemlendi. Alt ekstremite kas kuvvet eğitimleri daha çok çömelme ile uyluk fleksiyon ve ekstansiyon hareketinden oluşmakta idi. Alt ekstremite kassal kuvvet eğitimi (özellikle uyluk ve/veya baldır kaslarının) hoplama performansını olumlu etkilemesi beklenmektedir ${ }^{19}$. Çalışmaya katılan bireylerde düzenli vücut geliştirme sporu yapılmasına rağmen, kuvvet eğitiminin üst ekstremiteye odaklanması ve genetik faktörlerin etkisi ile bu sonuç elde edilmiş olabilir. Çünkü bu çalışmada beden algısı ile öne hoplama test sonuçları arasında bir ilişki olmaması rağmen, üst ekstremite sağlık topu firlatma performansı ile beden algısı arasında pozitif yönlü orta kuvvette bir ilişki bulunmuştur.Elde edilen bu sonuç ile vücut geliştirme sporu yapan genç bireylerin üst ekstremiteleri ilebeden imajlarını bütünleştirdikleri kanaatine varılmıştır.

Buke ve ark. tarafindan sağlık genç bireyler üzerinde üst ekstremite kuvvet, esneklik ve saha testleri arasındaki ilişkiyi incelemek amacıyla yapılan bir çalışmaya katılan yirmibeş erkek birey ile bu çalışmaya katılan bireylerin yaş ortalaması ve VKİ ortalamaları benzer olmasına rağmen sağlik topu firlatma mesafeleri bu 


\section{Ç. Sayaca ve Y.E. Sevgili}

çalışmada daha fazla olduğu saptand ${ }^{20}$. Bu çalışmaya katılan bireylerin sağlık topu firlatma mesafesinin yüksek olmasının temel sebebi çalışmaya katılan bireylerin vücut geliştirme sporu yapmalarından kaynaklanıyor olabilir. Fırlatma, kişiye özgü bir teknik olmasının dışında kor, üst ve alt ekstremite kuvvet ve gücün birlikte zamansal olarak ortaya çıkardıkları bir performans olup $^{21,22}$ üst ekstremite kassal kuvvet ile sağlık topu firlatma arasında kuvvetli bir ilişki olduğu saptanmıştır ${ }^{9,20}$. Vücut geliştirme sporu yapan bireyler eğitimlerinde üst ekstremite kassal kuvveti artırmaya yönelik egzersizler yaptıklarından elde edilen kassal kuvvet gelişimi sağlık topu firlatma performansını olumlu olarak etkilediğini düşünmekteyiz.

Vücut geliştirme sporu yapan bireylerin, bedenlerinin özellikle yüz ve ekstremiteleri ile ilgili sahip oldukları olumsuz fikirlerden dolayı ${ }^{7}$ çalışmaya katılan bireylerin çoğunlukla egzersiz eğitimleri sırasında üst ekstremitelerine daha fazla odaklandıkları görüldü. $\mathrm{Bu}$ sayede daha fazla kuvvet eğitimine maruz kalan üst ekstremite kaslarının kassal kuvvet ve dolayısıyla gücünde de artış sağlamaktadır. Bu çalışmada da üst ekstremite işlevsel performans sonucu olan sağlık topu firlatma mesafesi ile beden algisı arasında pozitif yönlü orta düzey bir ilişki bulundu. Bedenlerinde odaklandıkları vücut kısmının daha sıklıkla üst ekstremite olması sebebiyle alt ekstemitelerine yeteri kadar kuvvet eğitimine almadıklarından alt ekstremite işlevsel performansları ile beden algısı ölçek skoru arasında bir ilişki bulunamamış olabilir. Vücut geliştirme sporu yapan veya bu spora başlayan bireylerin hem alt hem de üst ekstremitelerinin önemini vurgulayan eğitimler verilerek ekstremiteler arasında ortaya çıkabilecek işlevsel performans dengesizliklerinin önlenmesinde ve sağlığın korunmasında önemli olabilir.

$\mathrm{Bu}$ çalışmanın bazı kısıtlılıkları bulunmaktadır. Çalışmaya benzer yaş aralığında sedanter bireylerin de kontrol grubu olarak alınması benzer yaş aralığındaki erkek bireylerin beden imajları ve ekstremite performanslarının karşılaştırılmasında önemli bilgiler sağlayabilir. Çalışmaya katılan bireylerin vücut geliştirme sporuna başlamadan önceki seviyeleri değerlendirilememiştir. Bu yüzden sporun etkisi araştırılamamıştır. Cinsiyetin ve özellikle eğitim düzeyinin de araştırılması gerektiğini düşünmekteyiz. Ayrıca, ekstremitelere ait kassal kuvvetin izokinetik benzeri objektif cihazlar ile ölçülmesi farklı bilgiler elde edilmesi ve gençlerin uygun egzersiz eğitimine alınmasında önemli bilgiler sunabilir.

Beden algısı, son yıllarda üzerinde durulan önemli konulardan biri olup bireyin bedenini zihinde nasıl göründüğüne dair sahip olduğu fikir, duygu ve düşünce olarak açıklanmaktadır. Üst ekstremite işlevsel performans düzeyindeki artış beden algısını olumlu etkilerken alt ekstremite işlevsel performans düzeyi ile beden algısı arasında herhangi bir ilişki bulunamadı.
Vücut geliştirme sporu yapan bireylerin beden algıları ayrıntılı değerlendirilmeli ancak vücut kısımları arasındaki dengeyi beden sağlığını ön plana alacak şekilde eğitim programları düzenlenmelidir.

\section{Teşekkür}

Çalışmaya katılmayı gönüllü olarak kabul eden ve destekleyen katılımcılara tüm yazarlar teşekkür eder.

Etik Kurul Onay Bilgisi:

Onaylayan Kurul: Üsküdar Üniversitesi Girişimsel Olmayan Arastırmalar Etik Kurulu.

Onay Tarihi: 23.02.2018

Karar No: 2018/415

\section{Kaynaklar}

1. Tylka TL, Wood-Barcalow NL. What is and what is not positive body image? Conceptual foundations and construct definition. Body Image. 2015;14:118-29.

2. Tok S, Güneş İ, Koyuncu M, Doğan B, Canpolat AM. The effect of female media body images on body image dissatisfaction in female athletes and nonathletes. Türkiye Klinikleri J Med Sci. 2011; 31(5):1049-56.

3. Gardner RM. Methodological 1ssues in assessment of the perceptual component of body image disturbance. British Journal of Psychology. 1996;87(2):327-337.

4. Gündoğan F. Sirozlu hastaların beden imajı ve benlik saygılarının değerlendirilmesi. (Yüksek Lisans Tezi), Abant izzet Baysal Üniversitesi, Bolu, 2006.

5. Grogan S. Body image and health. J Health Psychol. 2006;11(4):523-30.

6. Baysalling Ö. Vücut Geliştirme. İstanbul: İlpres Basın ve Yayın; 2000

7. Eraslan M, Aydoğan H. Vücut Geliștirme ve Fitness Merkezinde Spor Yapan Bireylerin Beden Bölgelerinden Hoşnut Olma Düzeylerinin Yaş ve Cinsiyet Değişkenlerine Göre İncelenmesi. CBÜ Bed Eğt Spor Bil Dergisi / CBU J Phys Edu Sport Sci. 2016;11(2)

8. Semmler JG, Enoka RM. Neural contribution to changes in muscle strength. Biomechanics in Sport. London: Blackwell Science Ltd; 2000.

9. Hackett DA, Davies TB, Ibel D, Cobley S, Sanders R. Predictiveability of the medicine ball chest throw and vertical jump tests for determining muscular strengt hand power in adolescents, Measurement in Physical Education and Exercise Science, 2018;22(1):79-87. DOI: 10.1080/1091367X.2017.1385462

10. Odabașı S. Üst Ekstremite Testleri. Bulgan Ç, Başar MA, çeviri editörleri. İnsan Performansında Fonksiyonel Testler. İstanbul: İstanbul Medikal Sağlık ve Yayıncılık Hiz. Tic. Ltd. Şti.; 2018.

11. Dingenen B, Truijen J, Bellemans J, Gokeler A. Test-retest reliability and discriminative ability of forward, medial and rotational single-leg hop tests. The Knee. 2019;26(5):978-987.

12. Özgür T. Kuvvet ve Güç Testleri. Bulgan Ç, Başar MA, çeviri editörleri. İnsan Performansında Fonksiyonel Testler. İstanbul: İstanbul Medikal Sağlık ve Yayıncılık Hiz. Tic. Ltd. Şti.; 2018.

13. Hovardaoğlu S. Vücut Algısı Ölçeği. Psikiyatri, Psikoloji, Psikofarmakoloji Dergisi, Testler Özel Eki. 1993;1(1):26-27.

14. Burgess G, Grogan S, Burwitz L. Effects of a 6-week aerobic dance intervention on body image and physical self-perceptions in adolescent girls. Body Image. 2006;3(1):57-66. 


\section{Performans Düzeyleri ile Beden Algısı İlişkisi}

15. Jankauskienė R, Kardelis K, Pajaujienè S. Muscle size satisfaction and predisposition for a health harmful practice in bodybuilders and recreational gymnasium users. Medicina (Kaunas). 2007;43(4):338-46.

16. Erdoganoglu Y, Tunc U. Vücut Geliştirme Egzersiz Programı Uygulayan Bireylerde Beden Algisı ve Benlik Saygısı. Spor Hekimliği Dergisi, 55(x):i-vii;2020 TurkishJournal of Sports Medicine DOI: 10.5152/tjsm.2020.163

17. Olivardia R, Pope HG Jr, Borowiecki III JJ, et al. Biceps and body image: the relationship between muscularity and selfesteem, depression, and eating disorder symptoms. Psycho Men Masc. 2004;5(2):112-20.

18. Leister I, Mattiassich G, Kindermann H, et al. Reference values for fatigued versus non-fatigued limb symmetry index measured by a newly designed single-leg hop test battery in healthy subjects: a pilot study. Sport Sci Health. 2018;14:105-113.
19. Hermassi S, Chelly MS, Wagner H, Fieseler G, Schulze S, Delank KS, Shephard RJ, Schwesig R. Relationships between maximal strength of lower limb, anthropometric characteristics and fundamental explosive performance in handball players. Sportverletz Sportschaden 2019;33(02):96-103.

20. Buke M, Unver F, Kabul EG. Relationships between strength, flexibility, and field tests of upper extremity in healthy individuals. Turk J Sports Med. 2019;54(2):117-23.

21. Hermassi S, Aouadi R, Khalifa R. et al. Relationships between the yo-yo intermittent recovery test and anaerobic performance tests in adolescent handball players. J Hum Kinet 2015;45:197205.

22. Wagner H, Buchecker M, vonDuvillard SP. et al. Kinematic description of elite vs. low level players in team-handball jump throw. J Sports Sci Med. 2010;9:15-23. 
